\title{
Application of The Hierarchical Multicriteria Analysis Method to The Study of Water Erosion (South of Azilal, Morocco)
}

Abdelouhed Farah ${ }^{1 *}$, Ahmed Algouti ${ }^{2}$, Abdellah Algouti ${ }^{3} \&$ Mohamed Ifkirne $^{4}$

${ }^{1234}$ University of Cadi Ayyad, Faculty of Sciences Semlalia, Department of Geology, Geoscience Geotourism Natural Hazards and

Remote Sensing Laboratory (2 GRNT), BP 2390, 40000, Marrakech, Morocco

Corresponding Author: Abdelouhed Farah, E-mail: farah6faragh@gmail.com

\section{ARTICLE INFORMATION}

Received: November 02, 2020

Accepted: January 20, 2021

Volume: 2

Issue: 1

DOI: $10.32996 /$ jeas.2021.2.1.2

\section{KEYWORDS}

AHP, GIS, Azilal, Morocco, Water erosion

\section{ABSTRACT}

This study aims to apply the process of the analytical hierarchy in geographic information system to the study of water erosion in the southern part of the Azilal region, Morocco. This method is an important tool to be used in the planning and management of natural risks; it has allowed us to obtain a multi-factorial sensitivity map to water erosion. This sensitivity map of erosive soil conditions in the study area shows that $6 \%$ of the area is (less) exposed to erosion risk while $85 \%$ of the mapped area is moderately exposed to erosion risk and only $8 \%$ of the mapped area is highly exposed to water weathering factors. Visually, the high-risk zones correspond to the area around "Oued Lakhdar" and its tributaries.

\section{Introduction}

Soil erosion is a real environmental problem, and several regions of Morocco suffer from this phenomenon especially in mountain areas. As a result, erosion has negative environmental impacts that affect water supply, reservoir storage capacity, agricultural, and ecological productivity. Erosion and landslides are a real problem in mountain basins with transported sediments being deposited in water reservoirs and river systems (Hochedez \& Le, 2016; Gall ,2016) Estimating the loss of soil erosion is often difficult due to the complex interaction of many factors such as climate, land cover, topography and human activities (Le bissonnais, 2000 ; Mabit \& Laverdiere, 2002 ; PAP/CAR , 1998) Our study area is located in the southern part of Azilal which characterized by an uneven relief with steep slopes, a semi-arid climate, accentuated deforestation and overgrazing subordinated, to an already poor vegetation cover. All these factors lead to strong erosion whose consequences on the catchment area are the downstream filling in by erosion products. In this study we have relied on Geographic Information Systems (GIS) and the multi-criteria hierarchical model (AHP) analysis method to calculate erosion factors and develop the final erosion map.

\subsection{Study area}

The study site is located in the south of the Hassan-I dam in the Moroccan High Atlas Mountains, $30 \mathrm{~km}$ of southwest of the town of Azilal $\left(31^{\circ} 45^{\prime} \mathrm{N}-31^{\circ} 50^{\prime} \mathrm{N}\right.$ and $6^{\circ} 45^{\prime} \mathrm{W}-6^{\circ} 51^{\prime} \mathrm{W}$ ) (Figure. 1), covers an area of 5300 hectare, and its altitudes vary between 760 and $1700 \mathrm{~m}$ (Agoumi \& Debbarh,2006). (Figure. 2). The area has a semi-arid climate, and rainfall varies between 300 and $750 \mathrm{~mm}$ depending on the year. Frost is not a rare occurrence in winter, the summer is very hot thanks to the scorching southwestern-eastern "chergui" winds that raise the mercury above $40^{\circ} \mathrm{C}$, these heat waves sometimes end in violent thunderstorms that refresh the soil.

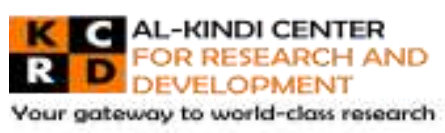

K C C AL-KINDI CENTER
R D FOR RESEARCH AND
Your gateway to world-class research

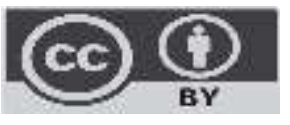

Published by Al-Kindi Center for Research and Development. Copyright (c) the author(s). This open access article is distributed under a Creative Commons Attribution (CC-BY) 4.0 license 


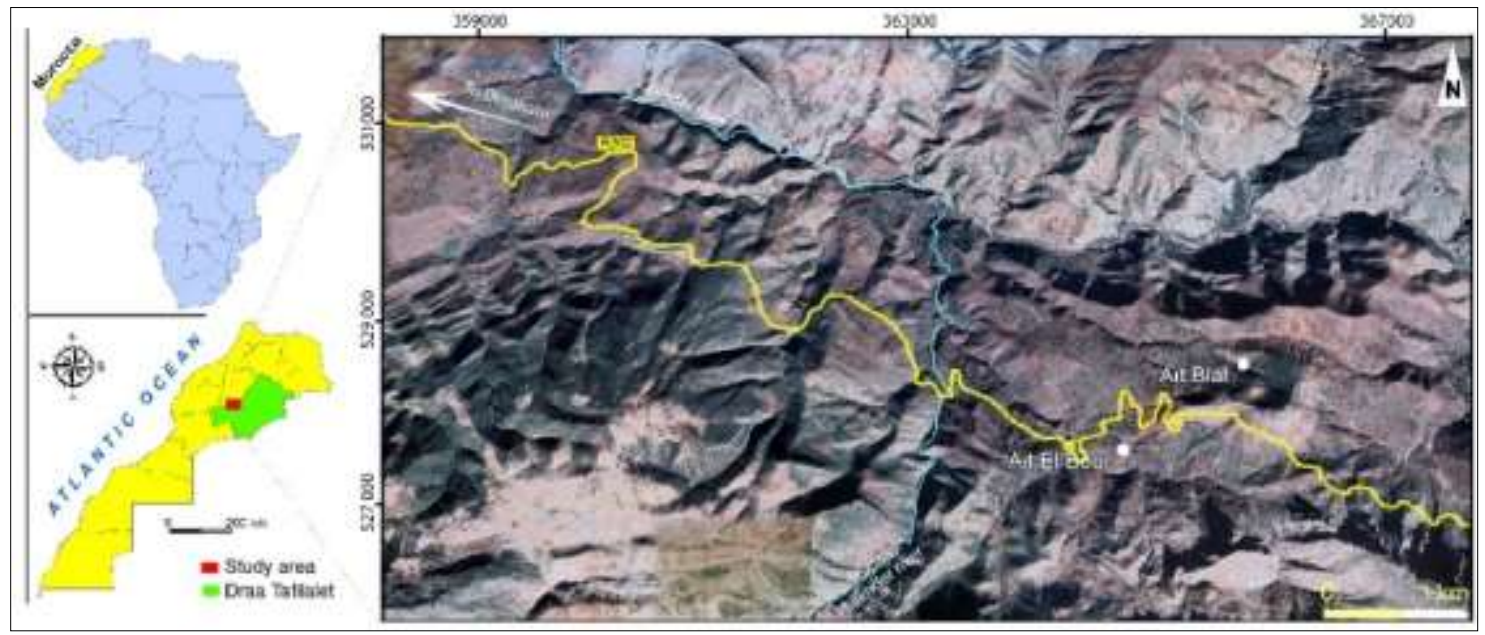

Figure 1: Geographic location of the study area.

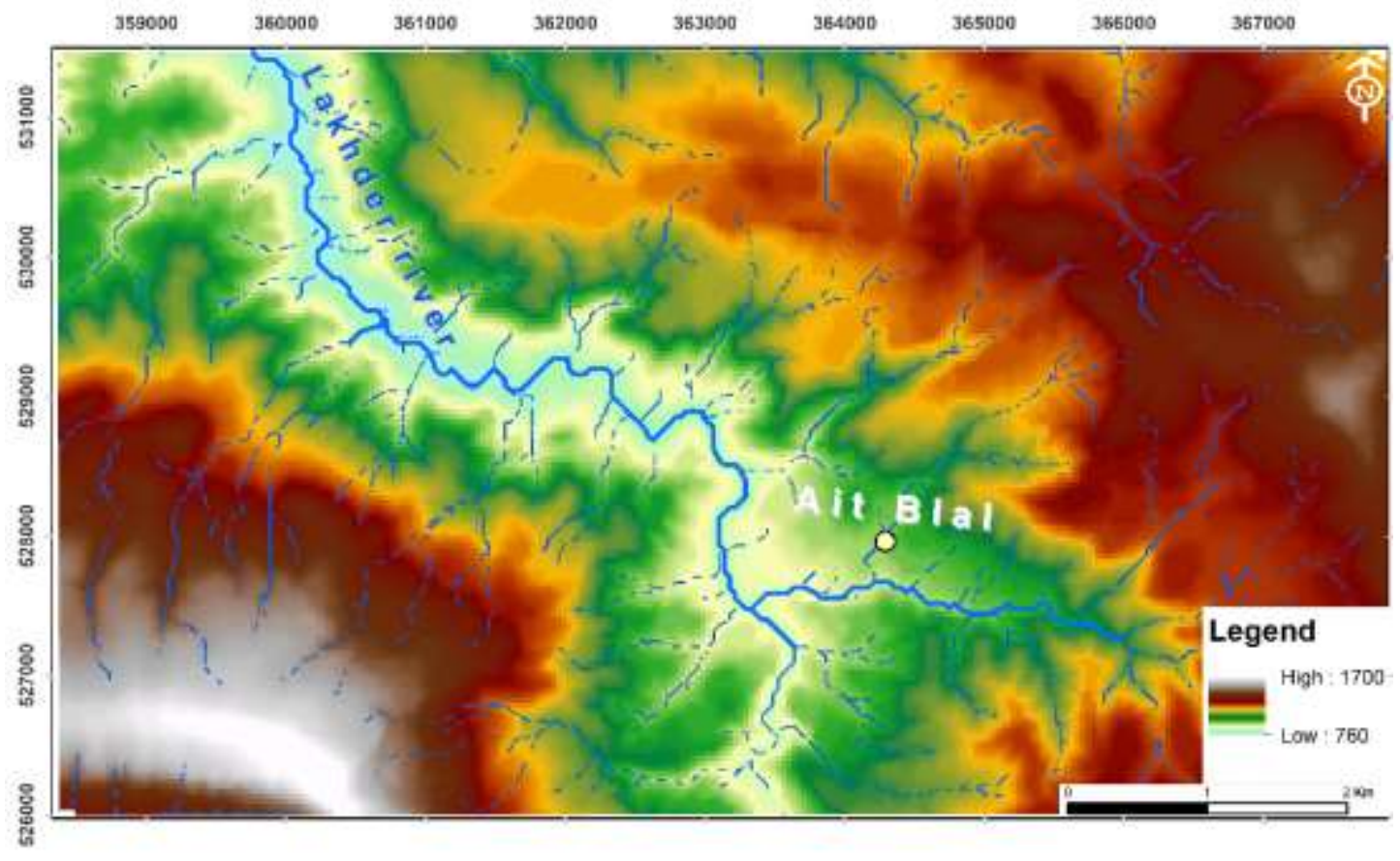

Figure 2: Map of altitude distribution of the study area.

\section{Data and Methodology}

The methodological approach followed in the present study (Figure.3), summarizes all the steps carried out from data acquisition to the edition of the final water erosion risk map (Figure.11). The data used in this work are as follows, The vegetation index (NDVI) calculated from the Landsat-8 Oli satellite image acquired on August 1, 2015 from the U.S. Geological Survey Earth Explorer has been made available for this study, for the slope, river network and sun exposure are extracted from STRM-type digital terrain modules (DEM) downloaded from the NASA USGS website and for the lithological description, at 1/50,000 geological map of Azilal was used. The image data has been corrected for various disturbing effects (atmosphere, sensor and topography) and standardized for proper integration with other related data in a geographic information system. 


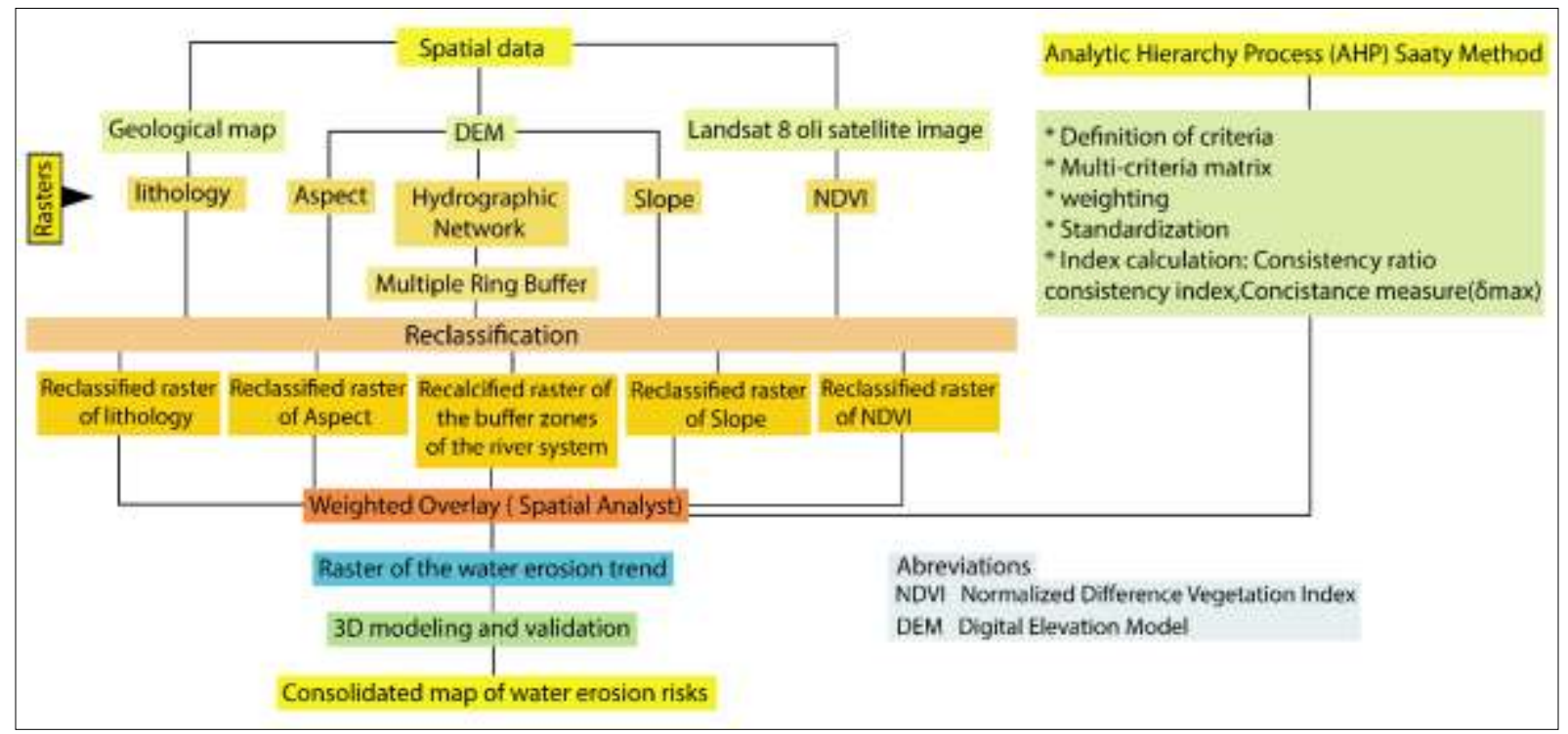

Figure 3: Flowchart of the methodology

\section{Results and discussion}

\subsection{Spatial processing and analysis}

The problem of water erosion is causing economic and ecological damage in the sub-watershed of the Azilal area. In order to develop the map of the erosive risk zones in the study area, we have taken into consideration the following factors that are responsible for water erosion.

\subsection{1-The slope gradient}

The slope map is one of the basic elements for the analysis of the characteristics of water erosion. Physical factors determine the sensitivity of areas to erosion. The gradient of the slopes strongly determines the potential for development and enhancement of the soil and thus contributes to the physical process and the emergence of water erosion. The slope map of the study area was established and transformed into a land erosion sensitivity map based on its gradient. Each slope class was assigned an index ranging from 1 to 3.1 is assigned to gentle slopes $\left(<10^{\circ}\right)$ and 3 to steep slopes $\left(>26^{\circ}\right)$, (Figure.4).

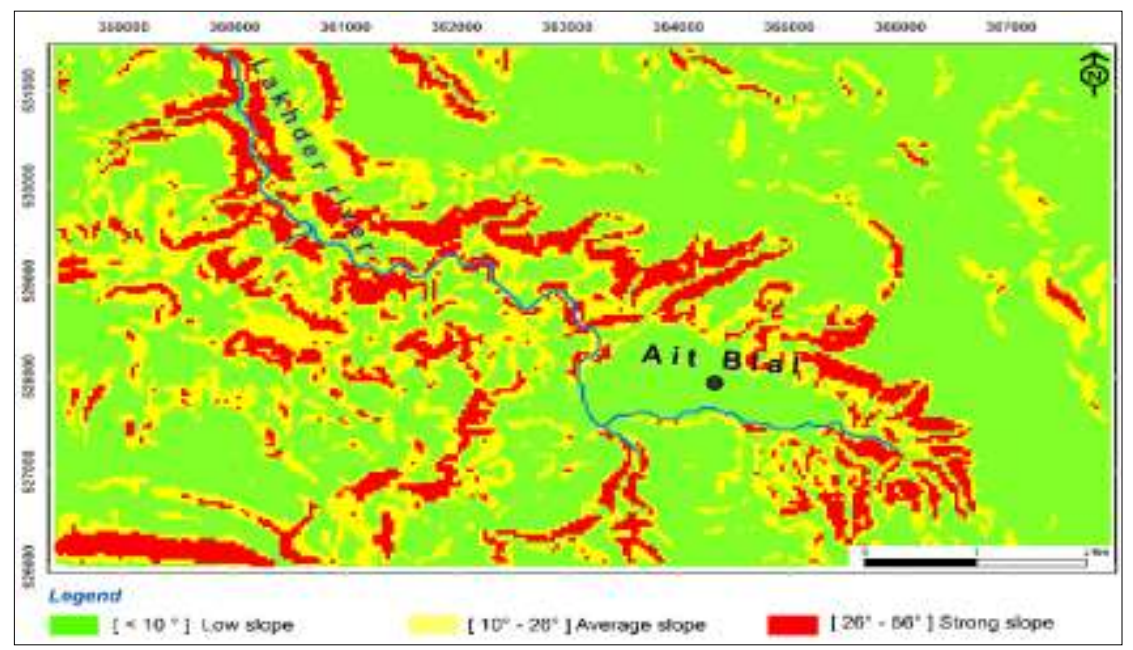

Figure 4: Water erosion sensitivity map as a function of slope, in green low risk, yellow medium risk and red high risk

The analysis of the slope map shows that the steep slopes generally outcrop at the level of the tributaries and around "Oued Lakhdar", these areas are highly threatened by water erosion. Therefore, the slope is a determining factor in the sensitivity to water erosion. (Table 1) 
Table 1: Classification and characteristic of the slope factor taken into account in the multi-criteria analysis.

\begin{tabular}{|c|c|c|}
\hline Interval in degrees & Class & Description \\
\hline $0-10^{\circ}$ & Low slope & $\begin{array}{r}\text { Corresponds to plain reliefs, alluvial terraces and structural flats. This } \\
\text { class is characterized by a low sensitivity to erosion. }\end{array}$ \\
\hline $10^{\circ}-26^{\circ}$ & Medium Slope & $\begin{array}{r}\text { Represents foothills, glacis reliefs, hills and is characterized by a } \\
\text { medium sensitivity to erosion. }\end{array}$ \\
\hline $26^{\circ}-56^{\circ}$ & Strong slope & $\begin{array}{r}\text { Corresponds to a mixed zone regrouping the upper foothills and } \\
\text { the mountains. This class includes lands characterized by a high } \\
\text { sensitivity to erosion. }\end{array}$ \\
\hline
\end{tabular}

\subsection{2-Covered with vegetation}

The process of erosion is closely linked to the way the land is used, which largely contributes to its aggravation or attenuation. It is known that the influence of vegetation cover on linear erosion is very important (Lavabre \& Andréassian,2000). Its action is more effective as it absorbs the kinetic energy of raindrops and slows down runoff or maintains good soil porosity. Vegetative cover has been divided into several classes in our study area (Figure 11.C). Each class was assigned a capacity to protect against water erosion. The different existing classes and their degree of sensitivity are as follows (Table 2)

Table 2: Classification and characteristics of the vegetation cover taken into account in the multi-criteria analysis

\begin{tabular}{|c|c|c|}
\hline Interval in degrees & Class & Description \\
\hline$(-0,06)-0,19$ & Low vegetation & $\begin{array}{l}\text { It includes the steppe and Saharan rangelands to the south, as well } \\
\text { as the clearing areas to the north and northwest of the watershed. } \\
\text { This class is defined as having a low soil protection capacity against } \\
\text { water erosion. }\end{array}$ \\
\hline $0,19-0,27$ & $\begin{array}{c}\text { Average } \\
\text { vegetation }\end{array}$ & $\begin{array}{c}\text { It corresponds to areas where the vegetation cover is mainly } \\
\text { composed of annual crops (cereals, extensive agriculture). This class } \\
\text { is assumed to have an average capacity to protect the soil against } \\
\text { water erosion. }\end{array}$ \\
\hline $0,27-0,54$ & $\begin{array}{c}\text { Strong } \\
\text { vegetation }\end{array}$ & $\begin{array}{c}\text { It includes forests, arboriculture and viticulture. This class is } \\
\text { considered to have a high soil protection capacity and therefore } \\
\text { justifies a low sensitivity to erosion. }\end{array}$ \\
\hline
\end{tabular}

The result of this classification is represented on the erosion sensitivity map defined as a function of vegetation cover (Figure.5).

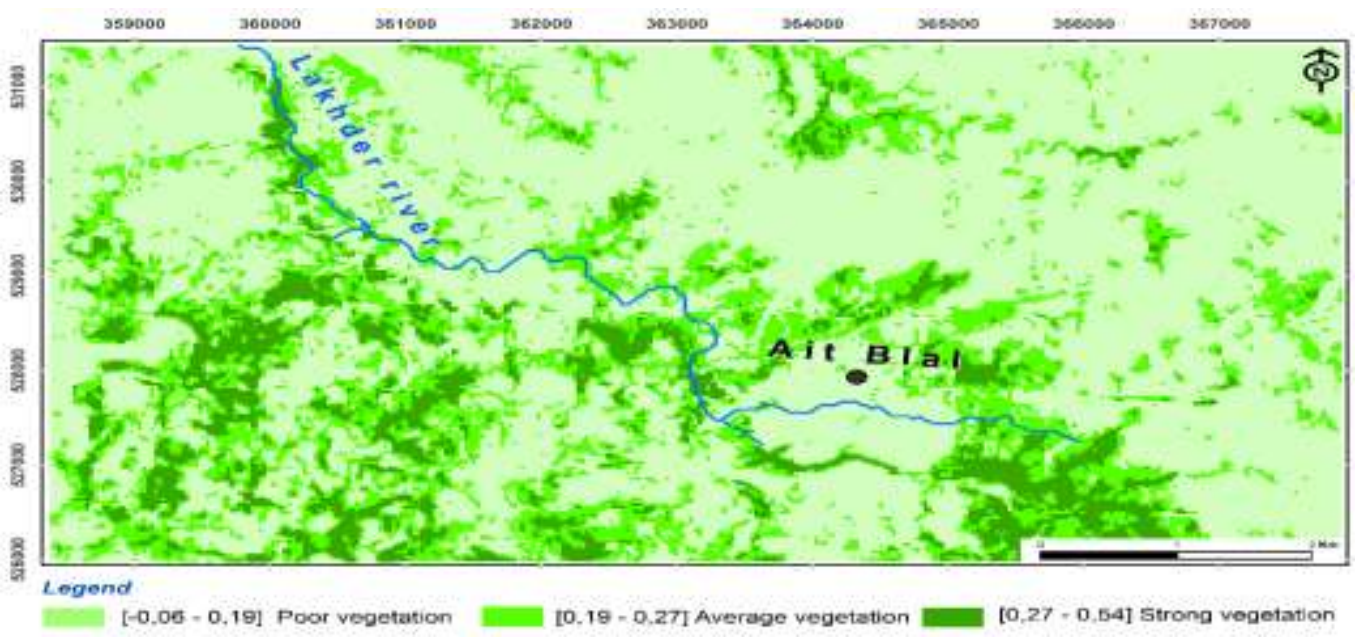

Figure 5: Map of sensitivity to water erosion as a function of vegetation cover, in light green high risk, medium risk green and dark green low risk 


\subsubsection{Erodability of geological materials}

The notion of erodability reflects the sensitivity of a soil to erosion with respect to its intrinsic properties. Erodibility is closely related to the infiltration capacity of the soil, the structural stability and the percentage of organic matter present (Blanchart,2004) Soil grain size plays an important role in the erodibility factor. That is to say that the more the silty fraction increases compared to clay and sand, the more erodible the soil becomes. Thus, in a soil with a stable structure and high organic matter content, the runoff rate decreases, consequently, the rate of erosion decreases as well. The classification includes 3 classes of increasing sensitivity to water erosion. (Table 3) (Figure.6)

Table 3: Classification and characteristic of the soil factor considered in the multi-criteria analysis

\begin{tabular}{|c|c|c|}
\hline Class & Degree of erosion & Description \\
\hline 1 & Low susceptibility to erosion & Sandstone \\
\hline 2 & Moderately sensitive to erosion & Limestone \\
\hline 3 & Highly sensitive to erosion & Alluvium \\
\hline
\end{tabular}

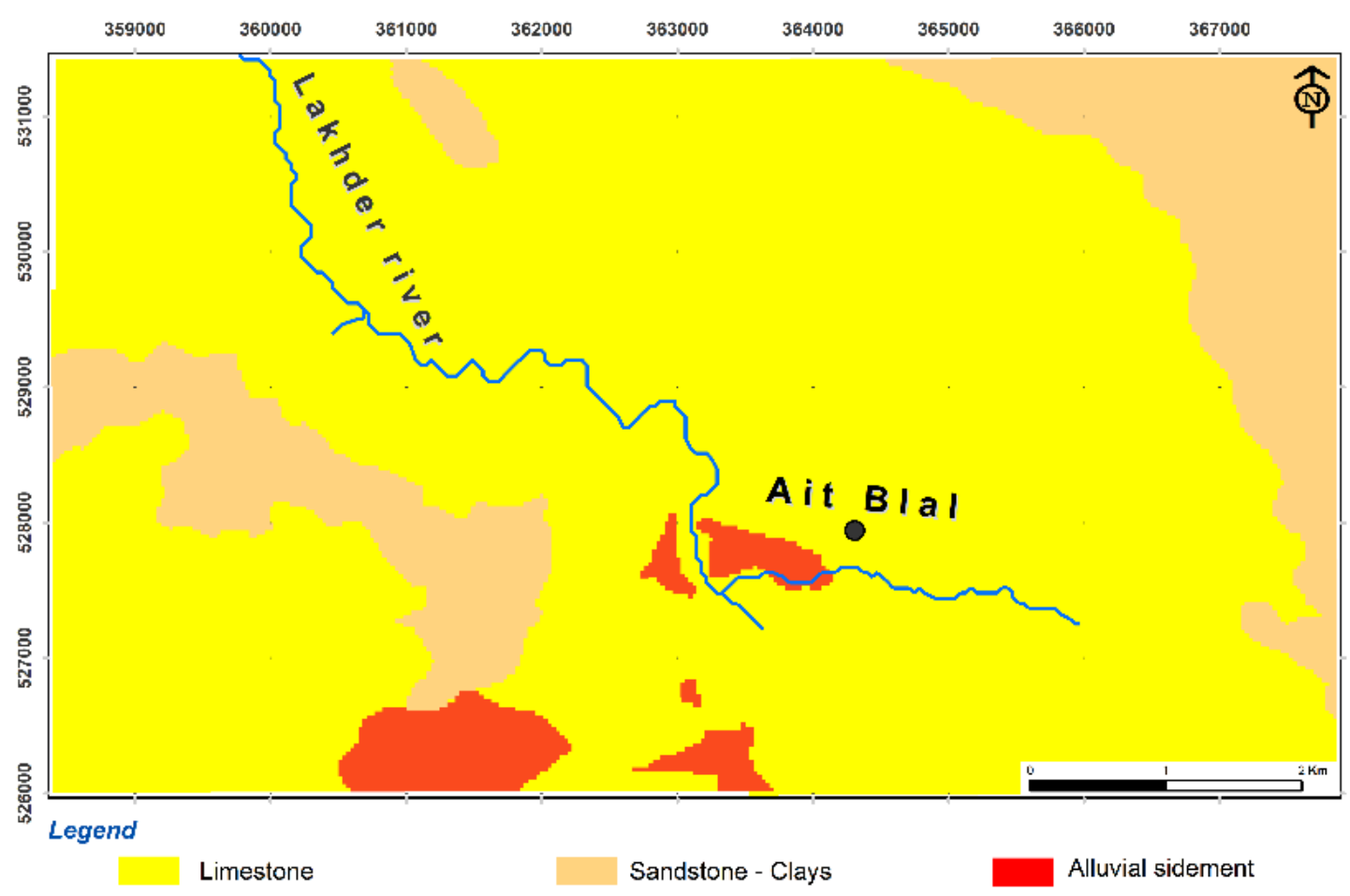

Figure 6: Map of sensitivity to water erosion as a function of lithological facies

\subsection{4-The hydrographic network}

The hydrographic network has been recognized as an essential agent of soil erosion (Hochedez \& Le, 2016; Leguédois,2003; Quansah, 1981). The energy and speed of the flow brought by the current lines are at the origin beyond the destructuring of the aggregates present on the banks of watercourses (Le Bissonnais, 1988). The flow of water in the hydrographic network is endowed with a certain energy that is used for sediment transport and digging. As long as the sediment load has not reached the equilibrium value beyond which the flow can no longer set new materials in motion, some energy is put to use in digging. Erosion in the river system is manifested by two processes: bed excavation and bank scouring (Figure11.B). The different existing classes and their degree of sensitivity are as follows (Table 4). 
Table 4: Classification and characteristic of the hydrological factor taken into account in the multi-criteria analysis.

\begin{tabular}{|c|c|c|}
\hline Class & Degree of erosion & Description \\
\hline$>80 \mathrm{~m}$ & Low risk of water erosion & $\begin{array}{l}\text { Includes areas far from the axis of watercourses at a } \\
\text { distance of at least } 80 \mathrm{~m} \\
25-80 \text { A medium Risk }\end{array}$ \\
\hline $25-80$ & Medium Risk water erosion & Includes areas at a distance of 25 to $80 \mathrm{~m}$ from the site. \\
\hline$<25 m$ & High Risk water erosion. & Includes areas closer to watercourses than $25 \mathrm{~m}$ away. \\
\hline
\end{tabular}

The factor related to the hydrographic network is less important than the other criteria given the unfavorable hydrological context of the study area (Figure7)

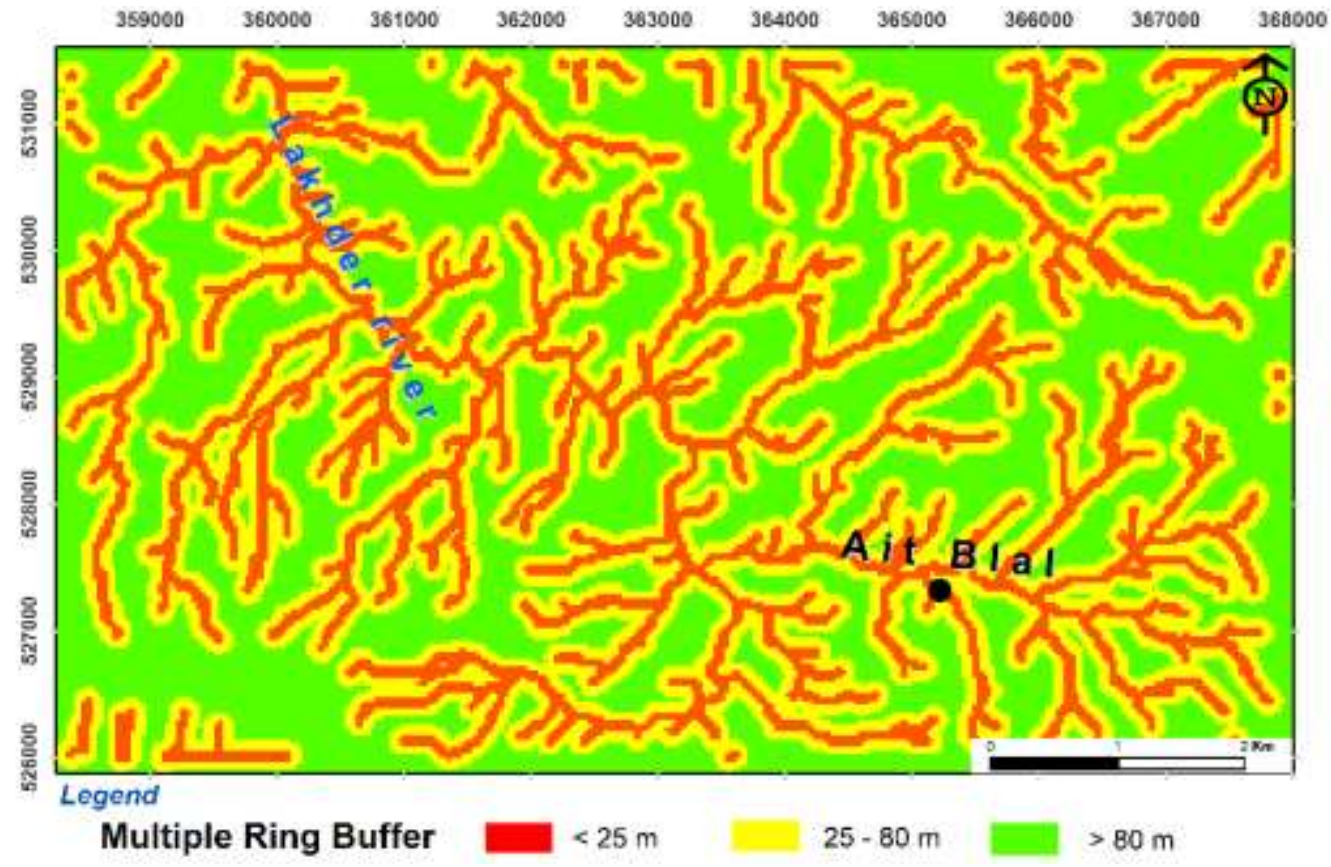

Figure 7: Water Erosion Sensitivity Map as a Function of River System

\subsubsection{The exhibition}

Exposure has influence on the risk of water erosion, the areas that are located in sunny sites (Figure 11.A) have the power to absorb solar energy, and make the place so exposed to change the intrinsic parameters of the soil (porosity, void index, granulometry ...). On the other hand, the shaded areas whose soil is wet promote the development of vegetation, and make the soil more resistant. Therefore, these areas are less exposed to the risk of erosion (Class 1). The different existing classes and their degree of sensitivity are as follows (Table 5). It is concluded that the exposure factor is one factor among others that has the ability to determine the frequency of water erosion (Figure.8).

Table 5: Classification and characteristic of the exposure factor taken into account in the multi-criteria analysis

\begin{tabular}{|c|c|c|}
\hline Class & Class Degree & Location \\
\hline 1 & Low Risk of erosion. & Nord-Plat-Nord-Ouest-Ouest \\
\hline 2 & Medium Risk of erosion. & South West-North East \\
\hline 3 & High Risk of erosion. & South-South-East \\
\hline
\end{tabular}




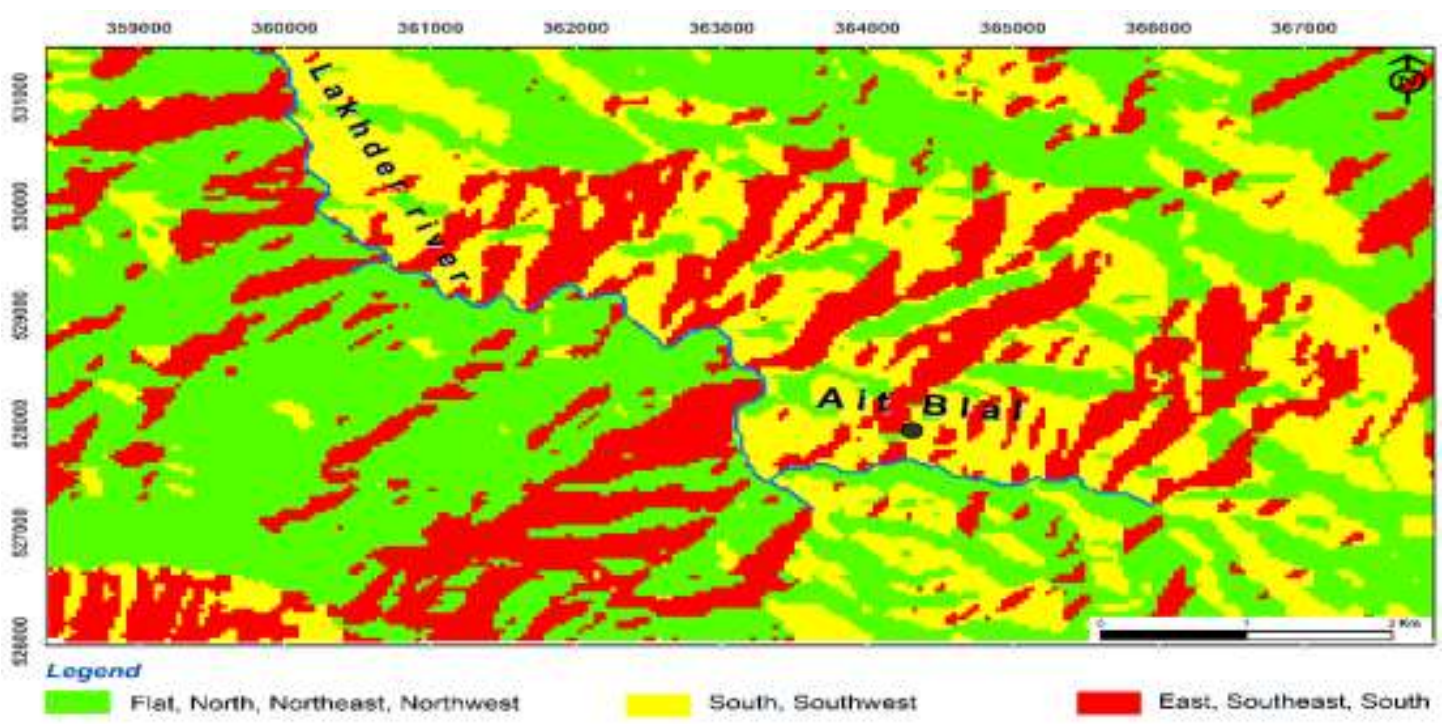

Figure 8: Map of sensitivity to water erosion as a function of slope exposure, in light green high risk, medium risk green and dark green low risk

\subsection{Multi-criteria analysis: Saaty method.}

The AHP method is a multi-criteria decision model which is based on the comparison by pairs of factors in the same hierarchical level. It is developed and used in the quantification of qualitative characteristics through its weighting (Ramos,2014; Saaty, 1991; Yalcin, Reis, Aydinoglu, \& Yomralioglu, 2011). The aforementioned method is used for many problems requiring decision making, some have even pointed out that this method has revolutionized the way complex problems are solved (Grandmont,2013; Saaty \& Sodenkamp,2010).For the AHP methodology, we used the following factors (Table 8): slope factor C3, exposure factor C5, soil pedology factor $\mathrm{C} 4$, water system factor $\mathrm{C2}$ and vegetation cover factor $\mathrm{C} 1$.The technique requires various steps such as decomposing the problem into sub-problems, highlighting the possible scenario (Figure.9) by standardizing the sub-criteria (Table 7), and elaborating a binary comparison matrix for each factor by specifying a scale from $1 / 9$ to 9 according to the importance of the parameter (Table 7). The weights attributed to the factors (Table 10) are judgments resulting from a good knowledge of the terrain and the control of the importance of the factors in the erosion process. It is necessary to calculate a consistency ratio (CR) to indicate the reliability of the judgments of the calculated matrix (Saaty, 1977). To show that the matrix is consistent, the value of the coherence ratio (RC) must be less than $0.1(10 \%)$. $R C$ is calculated by the following equation $\mathrm{RC}=$ $I C / R I$ where $(R C)$ is the coherence ratio, $(R I)$ is the random index developed by Saaty (Table 12) and (IC) is the coherence index calculated by the equation below $I C=\lambda \max -n / n-1 \lambda$ max: maximum eigenvalue of each factor in the matrix table and $n$ the size of the matrix (Table 6).

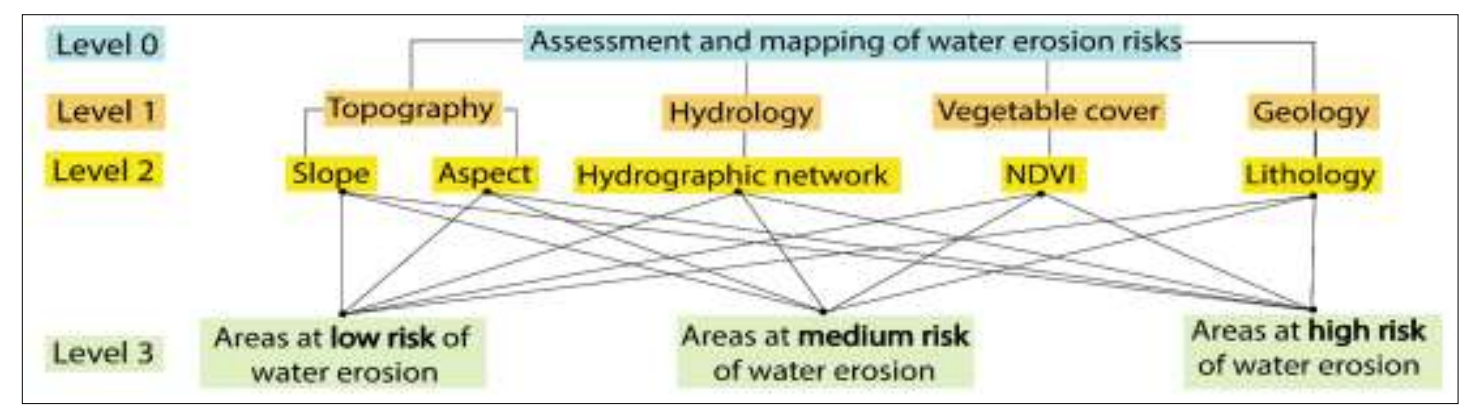

Figure 9: Identification of criteria, sub-criteria and alternatives

Table 6: Random consistency index by number of criteria.

\begin{tabular}{ccccccccc}
\hline $\mathbf{n}$ & $\mathbf{1}$ & $\mathbf{2}$ & $\mathbf{3}$ & $\mathbf{4}$ & $\mathbf{5}$ & $\mathbf{6}$ & $\mathbf{7}$ & $\mathbf{8}$ \\
\hline R.I & 0 & 0 & 0.58 & 0.90 & 1.12 & 1.24 & 1.32 & 1.41 \\
\hline
\end{tabular}


Table 7: Basis for standardization.

\begin{tabular}{|c|c|c|c|c|}
\hline Criteria & Under criteria & High risk & Medium risk & Low risk \\
\hline Geology & Lithology & Alluvium & Limestone & Sandstone and clay \\
\hline Hydrology & $\begin{array}{l}\text { Hydrographic } \\
\text { network }\end{array}$ & $<25$ meters & 25 - 80 meter & $>80$ meters \\
\hline $\begin{array}{l}\text { Vegetable } \\
\text { cover }\end{array}$ & NDVI & {$[(-0,06)-0,19]$} & {$[0,19-0,27]$} & {$[0,27-0,54]$} \\
\hline \multirow[t]{2}{*}{ Topography } & Slope & {$\left[26^{\circ}-56^{\circ}\right]$} & {$\left[10^{\circ}-26^{\circ}\right]$} & $<10^{\circ}$ \\
\hline & Aspect & East/Southeast/South & South/Southwest & $\begin{array}{c}\text { North/ } \\
\text { Northwest/Flat/Northeast }\end{array}$ \\
\hline
\end{tabular}

Table 8: Definition of criteria

\begin{tabular}{|c|c|}
\hline & Criteria \\
\hline C1 & vegetation index (NDVI) \\
\hline C2 & Hydrographic network \\
\hline C3 & Slope \\
\hline C4 & Lithology \\
\hline C5 & Aspect \\
\hline
\end{tabular}

Table 9: Comparison matrix

\begin{tabular}{|r|c|c|c|c|c|}
\hline Criteria & C1 & C2 & C3 & C4 & C5 \\
\hline C1 & 1 & 4 & 2 & 3 & 5 \\
\hline C2 & 0.25 & 1 & 0,33 & 0,5 & 2 \\
\hline C3 & 0,5 & 3 & 1 & 2 & 4 \\
\hline C4 & 0,33 & 2 & 0,2 & 1 & 3 \\
\hline C5 & 0,2 & 0,5 & 0,25 & 0,33 & 1 \\
\hline
\end{tabular}

Table 10: Weighting matrix

\begin{tabular}{|c|c|c|c|c|c|c|c|}
\hline & C1 & C2 & C3 & C4 & C5 & Total & Weight \\
\hline C1 & 0,44 & 0,38 & 0,49 & 0,44 & 0,33 & 2,08 & $42 \%$ \\
\hline C2 & 0,11 & 0,10 & 0,08 & 0,07 & 0,13 & 0,49 & $10 \%$ \\
\hline C3 & 0,22 & 0,29 & 0,24 & 0,29 & 0,27 & 1,31 & $26 \%$ \\
\hline C4 & 0,15 & 0,19 & 0,12 & 0,15 & 0,20 & 0,81 & $16 \%$ \\
\hline C5 & 0,09 & 0,05 & 0,06 & 0,05 & 0,07 & 0,31 & $6 \%$ \\
\hline
\end{tabular}

Table 11: Standardization matrix.

\begin{tabular}{|c|c|c|c|c|c|c|c|}
\hline & C1 & C2 & C3 & C4 & C5 & Total & Total/Weight \\
\hline C1 & 0,42 & 0,39 & 0,52 & 0,48 & 0,31 & 2,129 & 5,115 \\
\hline C2 & 0,10 & 0,10 & 0,09 & 0,08 & 0,12 & 0,495 & 5,023 \\
\hline C3 & 0,21 & 0,30 & 0,26 & 0,32 & 0,25 & 1,337 & 5,108 \\
\hline C4 & 0,14 & 0,20 & 0,13 & 0,16 & 0,19 & 0,815 & 5,060 \\
\hline C5 & 0,08 & 0,05 & 0,07 & 0,05 & 0,06 & 0,314 & 5,035 \\
\hline
\end{tabular}


Table 12: Result of the analysis and indices of its accuracy.

\begin{tabular}{|c|c|c|}
\hline Category & Priority & Rank \\
\hline NDVI & $42 \%$ & 1 \\
\hline Hydrographic network & $10 \%$ & 4 \\
\hline Slope & $26 \%$ & 2 \\
\hline Lithology & $16 \%$ & 3 \\
\hline Aspect & $6 \%$ & 5 \\
\hline \multicolumn{3}{|c|}{ consistency measure $(\delta \max )=5,06$} \\
\hline \multicolumn{3}{|c|}{ Consistency Ratio CR $=2 \%<10 \%$ Acceptable analysis } \\
\hline \multicolumn{3}{|c|}{ Consistency Index $\mathrm{Cl}=0,02$} \\
\hline
\end{tabular}

The integration of the analytical results on the Weighted Overlay tool and the formalization of a typology of sensitivity to water erosion are based on the crossing of the data taken into account in the process on which a logical combination with the different weights for each cited criterion. The overlaying of the layers allowed us to obtain a multi-factorial sensitivity map of water erosion of the study area in 2D (Figure.10) and 3D (Figure.11). (Figure.10)

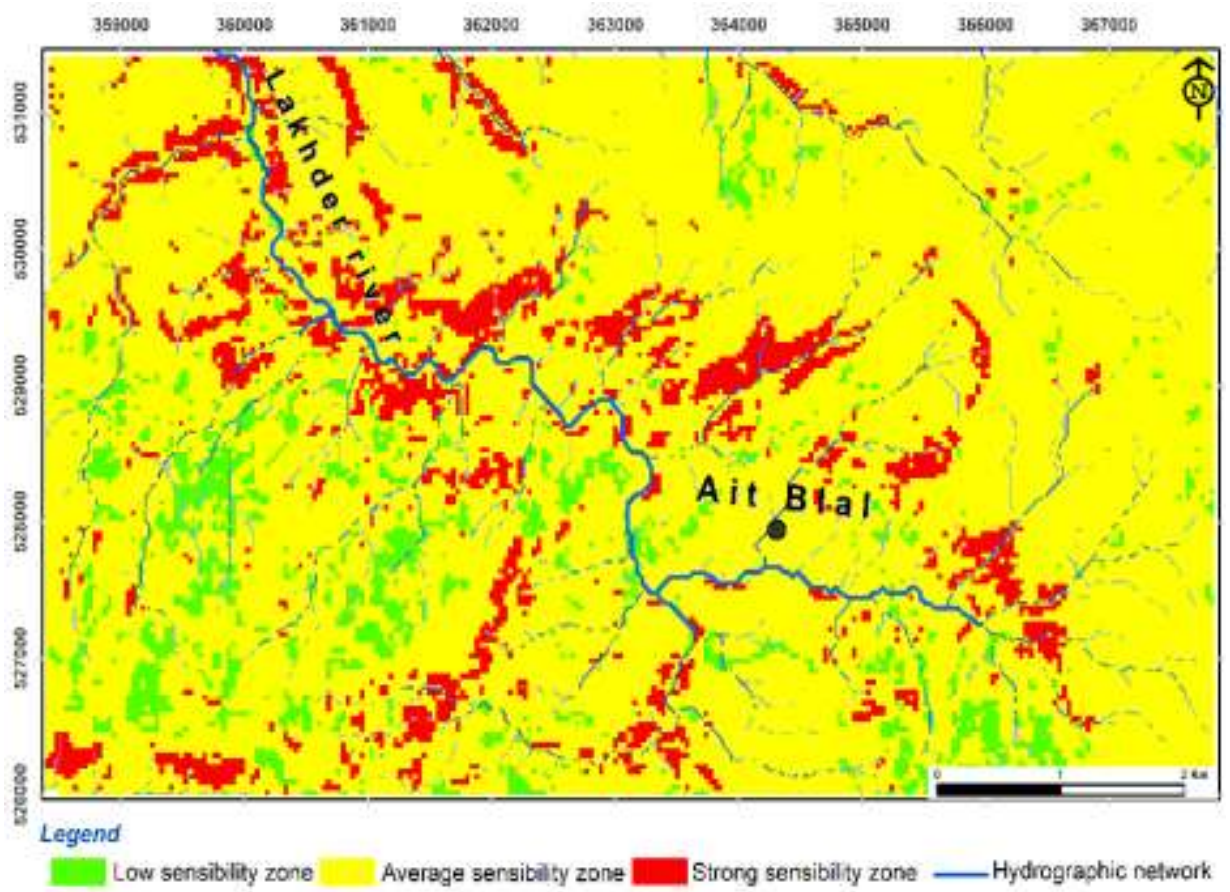

Figure 10: Thematic map of multifactorial sensitivity to water erosion in the study area

The analysis of the final map highlights areas of low water erosion. Sensitivity to water erosion represented in green color corresponds to lands with strong vegetation which spreads over a formation with low erodibility and has a low slope. The areas with medium sensitivity represent $85 \%$ of the land (yellow color); these areas have little vegetation, medium slopes $\left(26^{\circ}-56^{\circ}\right.$ ) and litho-logically corresponds to medium erodible lands of sandstone clay nature. On the other hand, the high sensitivity to erosion is shown in red on the map, these areas are characterized by fragile litho-logical facies (alluvium); very steep slopes and very poor vegetation. (Figure 11) 


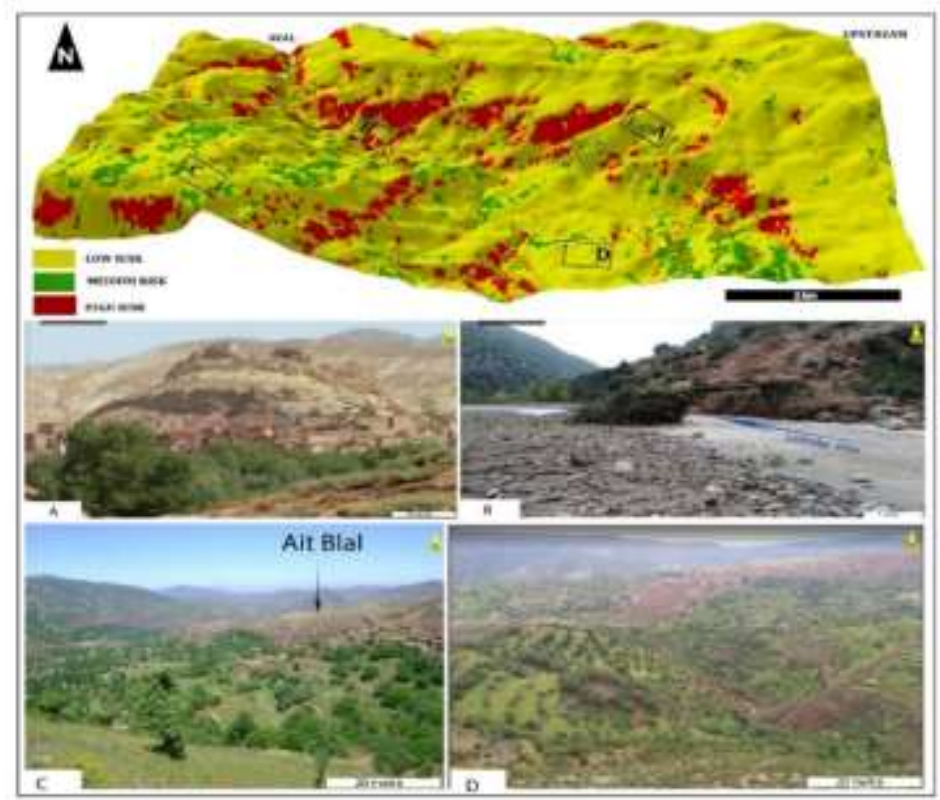

Figure 11: Water erosion sensitivity map of the study area in 3D with an exaggeration of 3 in the Vertical

\section{Conclusion}

In our study area, located in the watershed of the Azilal region, south of the 1st Hassan Dam, we used multi-criteria analysis (MCA) to highlight the parameters and to repair the soil degradation risks at the scale of the area. The mapping of areas at risk of soil degradation requires a perfect mastery of new geomatic tools, in particular GIS and remote sensing. The AHP multicriteria analysis method is in a complementary structured approach that process in an organized manner all the relevant information in order to assess the problem. This tool is presented as an orientation tool, capable of facilitating decisions and indicating areas undergoing degradation and erosion. A spatial database has been developed on the basis of a geological map, digital elevation, land use map, and a Landsat 8 satellite image in order to evaluate the different factors that may affect the analysis of soil degradation risks. However, uncertainties related to AHP techniques can have a significant impact on the results, depending on the choice of criteria and determining factors. The model was considered to be fairly satisfactory and can be used to estimate soil degradation rates. It has many advantages, as it makes an undeniable contribution to the risk of water erosion. It is presented as a simple and effective decision support tool to deal with this problem of soil loss. Finally, the AHP has shown that our study area is generally subject to a moderate risk of water erosion as previously studied in certain regions with a semi-arid climate

\section{Acknowledgements}

We would like to thank the NASA Land Processes Distributed Active Archive Center User Services, USGS Earth Resources Observation and Science (EROS) Center (https://LPDAAC.usgs.gov) for providing Satellite Data. The authors of this work are very grateful to the anonymous reviewers for their valuable comments and suggestions and to the editor of the journal for a careful review of the article which helped to present and work lucidly.

\section{References}

[1] Agoumi, A., \& Debbarh, A. (2006). Ressources en eau et bassins versants du Maroc : 50 ans de développement (1955-2005). 50 Ans de Développement Humains. Perspectives 2025.

[2] Blanchart, E., Albrecht, A., Brown, G., Decaens, T., Duboisset, A., Lavelle, P., ... \& Roose, E. (2004). Effects of tropical endogeic earthworms on soil erosion. Agriculture, Ecosystems \& Environment, 104(2), 303-315.

[3] GRANDMONT K. (2013). Utilisation de systèmes d'information géographique pour l'évaluation des risques liés à la dégradation du pergélisol. Étude de cas: Tasiujaq, Nunavik, Québec [Use of geographic information systems to assess the risks associated with permafrost degradation. Case study : Tasiujaq, Nunavik, Québec]. [MS Thesis]. Université de Montréal pp. 85.

[4] Hochedez, C., \& Le Gall, J. (2016). Justice alimentaire et agriculture: introduction. Justice spatiale-Spatial justice, (9).

[5] Lavabre, J., \& Andréassian, V. (2000). Eaux et forêts : la forêt, un outil de gestion des eaux ? (Vol. 1). Editions Quae

[6] Le GALL M., (2016). Traçage des sources de sédiments à l'amont des hydrosystèmes agricoles : apport de la géochimie élément : taire, du rapport Sr/Sr et des radionucléides «. Thèse de doctorat, L'UNIVERSITE PARIS-SACLAY ,261 p. 
[7] Le Bissonnais, Y. (1988). Analyse des mécanismes de désagrégation et de la mobilisation des particules de terre sous l'action des pluies (pp. 216-p). Université d'Orléans.

[8] LE BISSONNAIS Y., (2000). Analyse expérimentale des mécanismes d'érosion : la d dégradations structurale superficielle et le d étanchement des particules des sols cultivés. Ingénieries - E A T, N² 22 juin 2000.pp 27-36.

[9] Leguédois, S. (2003). Mécanismes de l'érosion diffuse des sols. Modélisation du transfert et de l'évolution granulométrique des fragments de terre érodés (Doctoral dissertation).

[10] Mabit, L., Laverdière, M. R., \& Bernard, C. (2002). méthodes et études de cas dans le Nord de la France. Cahiers agricultures, 11, $195-206$.

[11] PAP/CAR (1998). Directives pour la cartographie et la mesure des processus d'érosion hydrique dans les zones côtières méditerranéennes. PAP-8/PP/GL.1. Split, Centre d'activités régionales pour le Programme d'actions prioritaires (PAM/PNUE), en collaboration avec la FAO, $p$ : $\mathrm{XII+72.}$

[12] Quansah, C. (1981). The effect of soil type, slope, rain intensity and their interactions on splash detachment and transport. Journal of Soil Science, 32(2), 215-224.

[13] Ramos, A., Cunha, L., \& Cunha, P. P. (2014). Application de la Méthode de l'Analyse Multicritère Hiérarchique à l'étude des glissements de terrain dans la région littorale du centre du Portugal: Figueira da Foz-Nazaré. Geo-Eco-Trop, 38(1), 33-44.

[14] Saaty, T. L., (1977). A scaling method for priorities in hierarchical structures. Journal of Mathematical Psychology, 15(3), $234-281$.

[15] SAATY, T. L. (1991) - Método de Análise Hierárquica. São Paulo, McGraw-Hill, Makron. 367p. TOMLIN, C. D. 1991 - "Cartographic Modelling. In: GOODCHILD, M.; MAGUIRE, D. e RHIND, D. (Eds.) - Geographical Information Systems: Principles and Application. Harlow, Essex, UK : Longman Group, Ltd., 361-370.

[16] Saaty, T. L., \& Sodenkamp, M. (2010). The analytic hierarchy and analytic network measurement processes: the measurement of intangibles. In Handbook of multicriteria analysis (pp. 91-166). Springer, Berlin, Heidelberg.

[17] YALCIN A, REIS S, AYDINOGLU A.C \& YOMRALIOGLU T., (2011). A GIS-based comparative study of frequency ratio, analytical hierarchy process, bivariate statistics and logistics regression methods for landslide susceptibility mapping in Trabzon, NE Turkey. Catena 85 : $274-$ 287. 